\title{
Special issue on global sourcing of business and IT services
}

\author{
Julia Kotlarsky ${ }^{1}$, Leslie Willcocks ${ }^{2}$ \\ ${ }^{1}$ Aston Business School, Aston University, Birmingham, UK; \\ ${ }^{2}$ London School of Economics and Political Science, London, UK \\ Correspondence: \\ J Kotlarsky, Aston Business School, Aston University, Brimingham, B4 7ET, UK. \\ Tel: + 44121 2043116; \\ E-mail: j.kotlarsky@aston.ac.uk
}

Journal of Information Technology Teaching Cases (2012) 2, 57-60. doi:10.1057/jittc.2012.16; published online 13 November 2012

\section{From IT outsourcing to global sourcing}

ncreasing globalization and technological developments have contributed to the growth of the outsourcing and offshoring trends worldwide. These trends started in the late 1980s-early 1990s as Information Technology Outsourcing (ITO). This has been expanding to include Business Processes and Services (BPO), and today also covers a wide range of knowledge-intensive and strategic processes and services.

The global IT outsourcing ITO market has increased each year since 1989, when global ITO was only a US $\$ 9-\$ 12$ billion market. On conservative estimates, looking across a range of reports and studies, global IT outsourcing revenues will probably exceed $\$ 290$ billion in 2012 . With business process outsourcing revenues exceeding \$175 billion in the same year, and offshore outsourcing representing more than $\$ 85$ billion of these combined revenue figures, it is very clear that, with its 20 year plus history, outsourcing of IT and business services is moving into becoming an almost routine part of management, representing for many major corporations and government agencies the greater percentage of their back office expenditures.

Moreover, all projections we have looked at or made suggest continued growth over the next 5 years (2012-2016). Our own synthesis of the reports from Everest, Gartner, NASSCOM and IDC suggests that ITO global growth will be in the range of $5-8 \%$ per annum, with business process outsourcing rising by $8-12 \%$ per annum, and, subsumed within these, offshore outsourcing growing at an even faster annual rate. ${ }^{1}$

Client organizations continue to have a strong appetite for contracting with domestic, offshore and global BPO providers, and offshoring remains strong despite some reshoring pressures in developed countries. ${ }^{2}$ The year 2011 saw slowing of BPO growth in many markets with a pick up later into 2012. Some, but by no means all, are now experiencing growth rates above $12 \%$ per annum. In practice, offshoring and outsourcing often retain their scale through recessionary as well as growth periods, making them attr- active businesses for growing economies. A highly competitive global services market presents opportunities and revenues for countries able to offer the right mix of strong cost, reliable service and secure location.

The growth of outsourcing and offshoring affects all industries and organizations, and has also attracted the attention of governments and politicians who are frequently found arguing in favour, or against, these phenomena. In Western Europe and North America, opinions are divided between seeing outsourcing as a potential danger, for example, people losing their jobs that are moved offshore, and as potential benefits - lower costs, accessing skills in short supply, supporting increased scale of expanding businesses. In the developing economies - and we have identified over 120 offshore locations for IT and business services - outsourcing and offshoring are usually perceived positively as bringing new business, foreign investment, and facilitating job creation and economic growth in these countries.

\section{The expansion of courses on global sourcing}

The issues around global sourcing involve multiple players such as clients, suppliers and intermediaries who need to deal with contractual, operational and strategic aspects, as well as the soft (social) side of outsourcing relationships. All these stakeholders are interested in learning more about the characteristics of outsourcing and offshoring, how to avoid mistakes and how to achieve superior performance.

As a result, there is a fast developing interest in educational and training programmes in this area. While practitioners pay significant attention to global sourcing trends, as widely reflected in the commercial analyst reports, the academic world is starting to appreciate the importance of this trend by offering elective and core modules on MBA and Master level courses, as well as including this topic in their Executive education programmes. Practitioner groups like IAOP, CORE and NOA - are also alive to the demand. There are now several books that provide extensive 
backsourcing (Kotlarsky and Bognar) and innovation in outsourcing (Babin and Schuster), as well as the dynamic of the sourcing market that present challenges and opportunities for client and vendor firms (e.g., Carmel, Oshri, Su and Mao). The cases cover a wide range of industries. The cases vary in length, which will offer more opportunities for instructors to choose between longer and shorter cases (i.e., mini cases) depending on their teaching arrangements and time allocated to different topics. We provide an overview of cases included in this issue below. Readers should also note that JITTC cases in outsourcing and offshoring are not restricted to this special issue. Two major cases have been published in earlier JITTC issues. There are also two cases appearing in the next issue of JITTC that concern collaboration and partnership. The first is by Leslie Willcocks, David Feeny and Mary Lacity on the history of an enterprise partnership in the United Kingdom between BAE and Xchanging. The second is by Pamela Abbott, Jingqin Zheng and Rong Du, looking at innovation through collaboration in a Chinese context. These will be published in the new year online in JITTC volume 3.12013 (forthcoming).

In the present volume, the first case is by Valerie Jaiswal and Natalia Levina. It discusses outsourcing at J-TRADING - a US-based arm of a Japanese keiretsu (about 350 employees in the United States) focused on commodity trading between the East and North America. The company has experienced problems with its IT infrastructure and help desk functions. IT employees were not motivated to work on these rather mundane tasks leading to quality and cost issues. The CIO of J-TRADING decided to solve the problem by outsourcing both functions. The case describes J-TRADING's outsourcing journey through its ups and downs, discussing the process of vendor evaluation and selection, task transition, relationship management, and business outcomes. The case provides full financial details necessary for financial analysis and asks students to evaluate the sourcing decision itself as well as vendor selection and governance processes. It also asks students to elaborate on alternative sourcing approaches such as offshoring and cloud-based solutions.

Fang Su and Ji-Ye Maoco authored our second case about the market choices of a Chinese software services provider - ChITechcompany. This case describes the Chinese software-outsourcing vendor's struggle with its market choices, in response to the rippling effect of the global financial crisis. It also introduces Chinese software outsourcing vendors' capability development, market conditions and idiosyncrasies. ChilTech is representative of Chinese software vendors, in terms of its development history, environment conditions, experience of the financial crisis and countermeasures. Students can learn about the evolution and current status of the China-Japan software outsourcing industry through this case, and more specifically how vendors make market choices in a highly volatile market.

Our third case concerns backsourcing. Here Julia Kotlarsky and Lars Bognar first define backsourcing then discuss its many implications for organizations. Backsourcing requires the organization to manage organizational change, reintegrate knowledge, and develop new capabilities and competences. Taking into account that there is very limited empirical evidence of how to accomplish successfully the back-

sourcing process, two short case studies included in this new sourcing models such as crowdsourci (Carmel) and captive centres (Oshri), new trends such as 
teaching case offer additional insight into the process of backsourcing. The two case studies provide different examples. The first -MediaCorp - deals with backsourcing IT hosting services, which is considered a business process. The second - ITServCorp - examines bringing an IT product development back in-house. However, regardless of the nature of the backsourced activity, analysis of these two cases allows students to develop in-depth understanding of the process through which the backsourcing initiative has been implemented.

Our fourth teaching case by Ilan Oshri deals with the issue of shared service centres. In a search for an optimized global business service operation, firms set up and relocate shared service centres around the globe. This teaching case examines the migration process of an IBM procurement shared service centre from Budapest to Sofia. Oshri describes the challenges that the teams in Budapest and Sofia faced and the migration methodology applied, and later on adapted in order to meet the transition objectives. The case concludes by challenging IBM's migration approach, which students themselves can profitably discuss and analyse.

The focus of the fifth teaching case, by Ron Babin and Cheryl Schuster, is on building innovation into the outsourcing relationship when it has not been explicitly stated in the outsourcing agreement. The case is a composite of several actual outsourcing arrangements. Here the nomenclature of Bentley \& Brooks (B\&B) (the client) and AlphaCorp (the provider) is sued. $B \& B$ has outsourced much of their HR operations and IT support. They have been frustrated that their global outsource provider, AlphaCorp, has not been able to bring innovation to the relationship. In the outsourcing contract, innovation was not expressly identified, but was certainly discussed during the outsourcing proposal and negotiations. In addition, the ability of AlphaCorp to deliver consistent quality of service on a global basis has been uneven, particularly in Latin America. Students are asked how to deal with getting innovation from such outsourcing arrangements.

These five cases are large and detailed. The remaining three mini cases explore specific issues in several different countries. The Lifebushido case by Erran Carmel concerns a small US-based crowdsourcing platform and illustrates the entrepreneurial challenges in a new 'industry' - the crowdsourcing industry. The firm's President founded and manages a virtual firm. He launched the firm even before the term crowdsourcing was coined. He has chosen to focus his firm, initially, on selling labour services to the American real estate market. Now that has successfully built a network of reliable providers and his dilemma is: repeat clients and how to grow his firm.

The next mini case, written by Erran Carmel and Giovanni Vaia, discusses Healthware - a digital communication agency specializing in health care, based in Salerno, Italy. The firm has 72 employees in 2 countries, as well as clients in 14 countries. The case illustrates the location trade-offs of operating - and growing - a global digital company far from an epicentre Italian business. The theme is, in fact, a global one. Once the firm is far from a nation's epicenter a dynamism may be absent, but the advantages are quite tangible: lower costs and employee stability. This teaching case is based on actual companies, people and events, though some details have been dramatized or disguised.
The final mini case by Erran Carmel discusses the Peruvian Firm LOLIMSA. In 2005, this successful Peruvianbased software company was seeking to grow by exporting its software products. The case illustrates the entrepreneurial challenges in selling software products from a developing nation that is not on the forefront of the technology world. LOLIMSA has successfully grown its market into several Latin countries outside of Peru. The firm is considering trying to enter the lucrative American market for the second time, but knows that the investment in market entry has to be substantial.

\section{Concluding remarks}

All teaching cases in this special issue have detailed teaching notes that describe learning objectives, highlight target audiences and offer a wide range of questions for discussion (as well as sketch answers) that will enable instructors to choose questions relevant to the specific topic/module they are teaching. The teaching notes are available from the authors (emails of the corresponding authors are included on the first page of each case). Please note that proof of academic affiliation (instructor role) will be required to receive the teaching notes.

Furthermore, we ourselves have a wide range of resources that we have been developing and updating over years, in collaboration with our academic colleagues who teach modules on outsourcing and offshoring in the United States, Canada, the United Kingdom, the Netherlands, Ireland and several other European countries. The materials include slides that elaborate on and advance the topics discussed in our own Handbook (Oshri et al., 2011), learning tasks for class discussion and assignments that include real-life outsourcing project. Instructors interested in receiving these materials are welcome to contact us.

Finally, an invitation. If you have read this far you obviously take seriously the value and relevance of up-todate teaching cases. JIT Teaching Cases is now embarking on its third successful year as an electronic journal. If you are impressed by the quality and usefulness of its teaching cases, including those in this Special Issue, why not develop and submit your own? Or propose a Special Issue, of which you are willing to be Editor? Themes can be wide ranging and can be general management and strategy as well as about IT. What we are particularly looking for is cases that can be used across different courses and reflect interdisciplinarity. That said, teaching cases that focus on more accustomed information systems issues are very welcome indeed. JIT (JITTC) now has a case library of over 50 cases, but there is always the need for new cases as global events overtake us, as markets and contexts change, and as new issues arise.

\section{Notes}

1 Figures on size of ITO and BPO vary considerably depending on source and basis of calculation. We propose a composite figure based on the more conservative estimates, and our data from the LSE Outsourcing Unit database case on recent developments. See Willcocks and Lacity (2012), especially Chapter 1.

2 In fourth quarter of 2011, Khan and Lacity (2012) administered a survey to respondents representing 84 client organizations that 
purchase ITO and BPO services. Nine countries were represented, but the data primarily captured US client responses. Overall, they found that client organizations were not changing their buying patterns because of anti-offshoring pressures. Instead, client respondents reported strong satisfaction with offshore outsourcing of IT and business services and favourably reported on the costs savings and increased flexibility with offshore ITO and BPO. See: Khan and Lacity (2012).

\section{References}

Khan, S. and Lacity, M. (2012). Survey Results: Are Client Organizations Responding to Anti-Offshoring Pressures? Strategic Outsourcing: An International Journal 5(2): 166-179.

Oshri, I., Kotlarsky, J. and Willcocks, L.P. (2011). The Handbook of Global Outsourcing and Offshoring, 2nd edn London: Palgrave Macmillan.

Willcocks, L. and Lacity, M. (2012). Advanced Outsourcing Practice: Rethinking ITO, BPO and cloud services, London: Palgrave Macmillan. 